NASA/TM-2007-214969

\title{
RF Performance of Membrane Aperture Shells
}

Eric M. Flint and Jason E. Lindler

Mevicon, Inc., Palo Alto, California

David L. Thomas

M evicon, Inc., Gardnerville, Nevada

Robert Romanofsky

Glenn Research Center, Cleveland, Ohio 


\section{NASA STI Program . . . in Profile}

Since its founding, NASA has been dedicated to the advancement of aeronautics and space science. The NASA Scientific and Technical Information (STI) program plays a key part in helping NASA maintain this important role.

The NASA STI Program operates under the auspices of the Agency Chief Information Officer. It collects, organizes, provides for archiving, and disseminates NASA's STI. The NASA STI program provides access to the NASA Aeronautics and Space Database and its public interface, the NASA Technical Reports Server, thus providing one of the largest collections of aeronautical and space science STI in the world. Results are published in both non-NASA channels and by NASA in the NASA STI Report Series, which includes the following report types:

- TECHNICAL PUBLICATION. Reports of completed research or a major significant phase of research that present the results of NASA programs and include extensive data or theoretical analysis. Includes compilations of significant scientific and technical data and information deemed to be of continuing reference value. NASA counterpart of peer-reviewed formal professional papers but has less stringent limitations on manuscript length and extent of graphic presentations.

- TECHNICAL MEMORANDUM. Scientific and technical findings that are preliminary or of specialized interest, e.g., quick release reports, working papers, and bibliographies that contain minimal annotation. Does not contain extensive analysis.

- CONTRACTOR REPORT. Scientific and technical findings by NASA-sponsored contractors and grantees.
- CONFERENCE PUBLICATION. Collected papers from scientific and technical conferences, symposia, seminars, or other meetings sponsored or cosponsored by NASA.

- SPECIAL PUBLICATION. Scientific, technical, or historical information from NASA programs, projects, and missions, often concerned with subjects having substantial public interest.

- TECHNICAL TRANSLATION. Englishlanguage translations of foreign scientific and technical material pertinent to NASA's mission.

Specialized services also include creating custom thesauri, building customized databases, organizing and publishing research results.

For more information about the NASA STI program, see the following:

- Access the NASA STI program home page at http://www.sti.nasa.gov

- E-mail your question via the Internet to help@sti.nasa.gov

- Fax your question to the NASA STI Help Desk at 301-621-0134

- Telephone the NASA STI Help Desk at 301-621-0390

- Write to: NASA Center for AeroSpace Information (CASI) 7115 Standard Drive Hanover, MD 21076-1320 


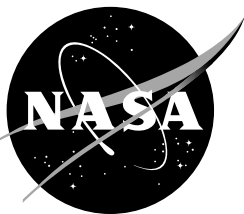

\section{RF Performance of Membrane Aperture Shells}

Eric M. Flint and Jason E. Lindler

Mevicon, Inc., Palo Alto, California

David L. Thomas

M evicon, Inc., Gardnerville, Nevada

Robert Romanofsky

Glenn Research Center, Cleveland, Ohio

Prepared for the

48th Structures, Structural Dynamics, and Materials Conference

cosponsored by the AIAA, ASME, ASCE, AHS, and ASC

Waikiki, Hawaii, April 23-26, 2007

National Aeronautics and

Space Administration

Glenn Research Center

Cleveland, Ohio 44135 


\section{Acknowledgments}

Some of the material contained in this report is based upon work supported by the United States Air Force under Contract No. FA9453-06-M-0155.

Level of Review: This material has been technically reviewed by technical management.

Available from

NASA Center for Aerospace Information 7115 Standard Drive

Hanover, MD 21076-1320
National Technical Information Service 5285 Port Royal Road Springfield, VA 22161

Available electronically at http://gltrs.grc.nasa.gov 


\title{
RF Performance of Membrane Aperture Shells
}

\author{
Eric M. Flint and Jason E. Lindler \\ Mevicon, Inc. \\ Palo Alto, California 94303 \\ David L. Thomas \\ Mevicon, Inc. \\ Gardnerville, Nevada 89460 \\ Robert Romanofsky \\ National Aeronautics and Space Administration \\ Glenn Research Center \\ Cleveland, Ohio 44135
}

\begin{abstract}
This paper provides an overview of recent results establishing the suitability of Membrane Aperture Shell Technology (MAST) for Radio Frequency (RF) applications. These single surface shells are capable of maintaining their figure with no preload or pressurization and minimal boundary support, yet can be compactly roll stowed and passively self deploy. As such, they are a promising technology for enabling a future generation of RF apertures. In this paper, we review recent experimental and numerical results quantifying suitable RF performance. It is shown that candidate materials possess metallic coatings with sufficiently low surface roughness and that these materials can be efficiently fabricated into RF relevant doubly curved shapes. A numerical justification for using a reflectivity metric, as opposed to the more standard RF designer metric of skin depth, is presented and the resulting ability to use relatively thin coating thickness is experimentally validated with material sample tests. The validity of these independent film sample measurements are then confirmed through experimental results measuring RF performance for reasonable sized doubly curved apertures. Currently available best results are $22 \mathrm{dBi}$ gain at $3 \mathrm{GHz}$ (S-Band) for a $0.5 \mathrm{~m}$ aperture tested in prime focus mode, $28 \mathrm{dBi}$ gain for the same antenna in the C-Band (4 to $6 \mathrm{GHz}$ ), and $36.8 \mathrm{dBi}$ for a smaller $0.25 \mathrm{~m}$ antenna tested at $32 \mathrm{GHz}$ in the Ka-Band. RF range test results for a segmented aperture (one possible scaling approach) are shown as well. Measured antenna system actual efficiencies (relative to the unachievable) ideal for these on axis tests are generally quite good, typically ranging from 50 to $90 \%$.
\end{abstract}

rms surface figure error

\section{Nomenclature}

wavelength

material conductivity

material thickness

impedance of free space.

antenna system efficiency factor

aperture area

aperture diameter

actual antenna system gain (in base $10 \mathrm{dBi}$ )

nominal ideal gain of antenna system (in base $10 \mathrm{dBi}$ )

half power beam width

$\mathrm{r} \quad$ RF reflectivity 


\section{Introduction}

Radio Frequency (RF) waves are widely used in many aspects of terrestrial and space based science (earth observation to space astronomy) and also have obvious application in the radar and communication industry. While the RF portion of the electromagnetic spectrum covers a very broad range (typically considered to range from $3 \mathrm{KHz}$ to $100 \mathrm{GHz}$, or ELF to the $\mathrm{W}$-band in EHF), in this paper we are primarily interest in the 1 to $100 \mathrm{GHz}$ (L to W band) range, or wavelengths of 300 to $3 \mathrm{~mm}$. While there are a wide range of antenna configurations possible ${ }^{1}$, in this operating regime, many high gain apertures are realized with a tailored feed coupled to a properly shaped passive dish reflector. On going science and mission performance driven demands for higher gain apertures make even larger apertures desirable. Such apertures are beneficial as they can provide better resolution, but even more importantly, better signal to noise ratios and/or reduced sidelobe levels for both transmit and receive mode. Launch vehicle size limitations however rapidly drive designers to antenna architecture that can be compactly stowed and reliably deployed/operated. While hinged solid panel based solutions have been considered from time to time, wire mesh based antenna approaches are currently the dominant solution in the low to mid GHz range due to their low mass and flight heritage. Relative to these state of the art wire mesh type approaches ${ }^{2}$ for compactly stowable large RF apertures, continuous surface apertures offer however the possibility of reduced sidelobe grating effects, higher frequency operation, and depending on configuration even simpler deployment. These driving requirements (compact stowage, larger continuous surface areas, simple deployment) have motivated research into the possible application of thin film based inflatable (in fact some of the first US satellites, Echo I and II were thin film based spherical passive RF reflectors ${ }^{3}$ ) and Gossamer Structure ${ }^{4}$ technology to provide large RF apertures, especially for space applications. Because of their promise, a wide range of potential thin film based system architectures such as tensioned flats (synthetic aperture arrays ${ }^{5}$, reflect arrays ${ }^{6}$ and waveguide ${ }^{7,8}$ approaches), singly curved troughs ${ }^{9,10}$, and doubly curved (pressurized ${ }^{11,12,13}$, space rigidized ${ }^{14,15,16}$, or electrostatically controlled ${ }^{17}$ ) lenticulars have been investigated by various organizations over the years for their suitability for realizing large RF reflective apertures for various applications (See Lou et al. ${ }^{18}$ for a concise overview (up to circa 2001) for many of these concepts).

\section{Background: Membrane Aperture Shell Technology (MAST)}

A relatively new type of gossamer structure, single surface membrane shells, are felt by the authors to offer strong promise. While starting from the same basic polyimide or polyester substrate as most other gossamer technology approaches, through a proprietary fabrication process, RF relevant doubly curvature is permanently induced into the material resulting in a load bearing structure that requires minimal support (i.e. no tension systems, no pressurization systems) to maintain its shape. In fact, at certain sizes and prescriptions, the resulting membrane shells are entirely self supporting and can be used with minimal support (Figure 1).

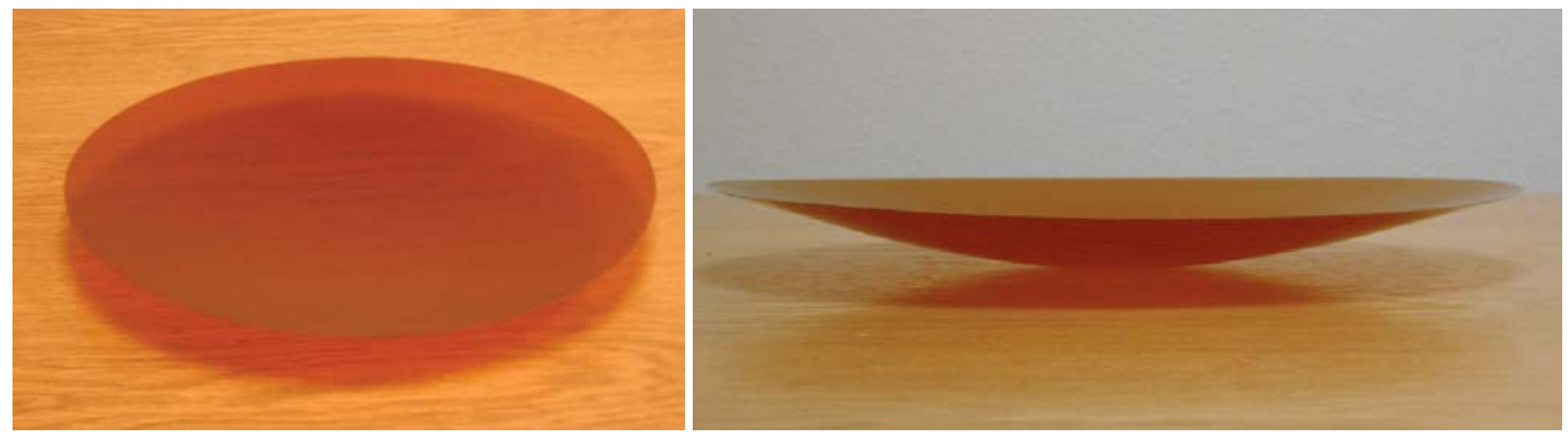

Figure 1: Various views of a sample deep MAST aperture supporting its own mass in 1-G

An added advantage of curvature stiffened shells is that due to their thin nature, the thin film surfaces can be compactly roll stowed and, upon release, passively self deploy. The latter fact dramatically reduces the need for pressurization or thermally driven shape memory deployment subsystems and power/time intensive in-space rigidization techniques (such as thermal, UV, or outgassing of solvents) typical of most alternative thin film techniques. A basic overview of the envisaged chain of use is provided in Figure 2. The shown aperture is a $0.5 \mathrm{~m}$ diameter R\#1.2 shell, supported on 8 discrete boundary mounts, with a film surface areal density of $175 \mathrm{~g} / \mathrm{m}^{2}$. Based on the previously published results ${ }^{19}$, there does not appear to be any fundamental physical limits (structural, stowage, or deployment) on aperture size to at least the $4+\mathrm{m}$ size for terrestrial applications (gravity loading case) and at least $20 \mathrm{~m}$ size for space applications (launch vehicle stowage constraints). Even larger sizes should be possible with investments in fabrication and alternative packaging and stowage methods. Originally under development to address the desire for mass/inertia savings for optical aperture applications (an overview of the 
current status of membrane aperture shell technology is provided in Figure 3), the same metallic coatings that provide good optical reflectance performance for membrane shells appeared promising for use to enable RF performance. Substrate materials with suitably low thickness variation have been identified, the ability of such materials (with suitable reflective coatings) to make optically powered surfaces has been interferometrically measured, the ability to fabricate these materials and coatings into a range of useful diameters $(0.1$ to $0.75 \mathrm{~m}$ currently demonstrated with plans for $1.1+$ to $2 \mathrm{~m}$ shells in development) and prescriptions (shown shells range from R\#'s of 0.9 to 2.2), and the ability to discretely mount such shells have all been demonstrated. Being based on polyimide or polyester thin films, membrane aperture shell technology apertures have extremely low areal densities. For just the surface itself, areal densities tend to range from 35 to $175 \mathrm{~g} / \mathrm{m}^{2}$. As already noted, supplementing this advantage is the additional fact that, also due to their thinness, these shells can be compactly roll stowed with no observed damage to figure or coatings.

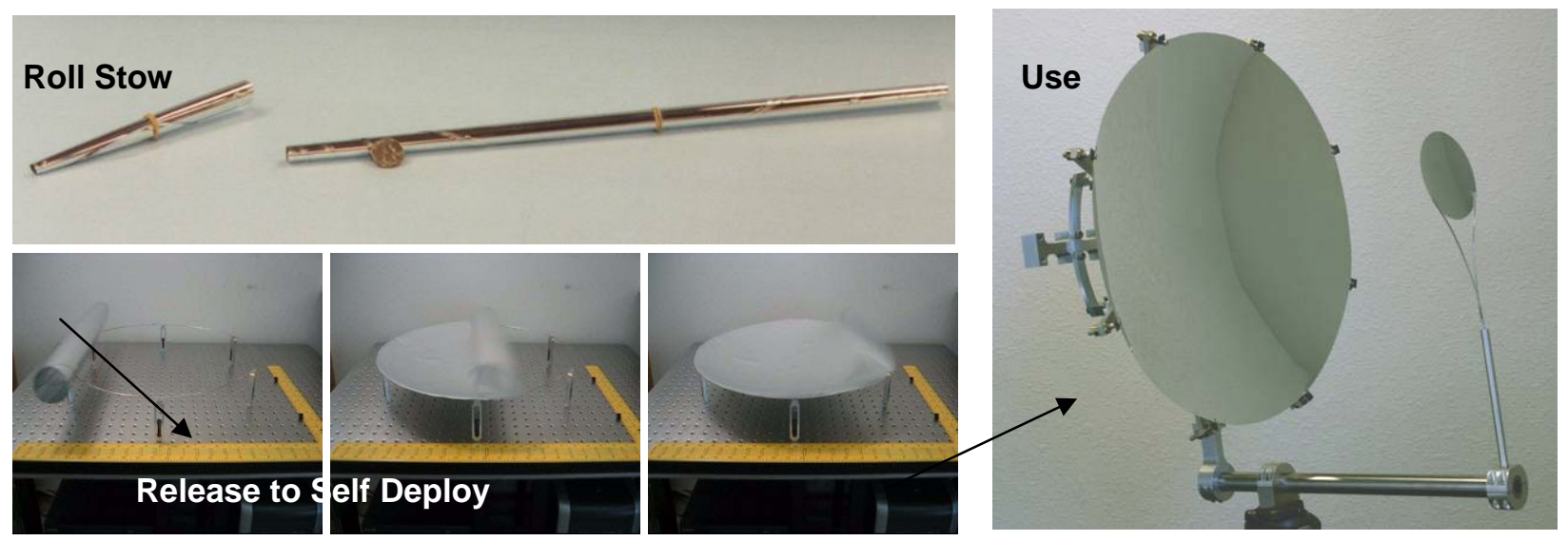

Figure 2: Basic MAST use concept: compact roll stowage, passive self deployment, minimal support.

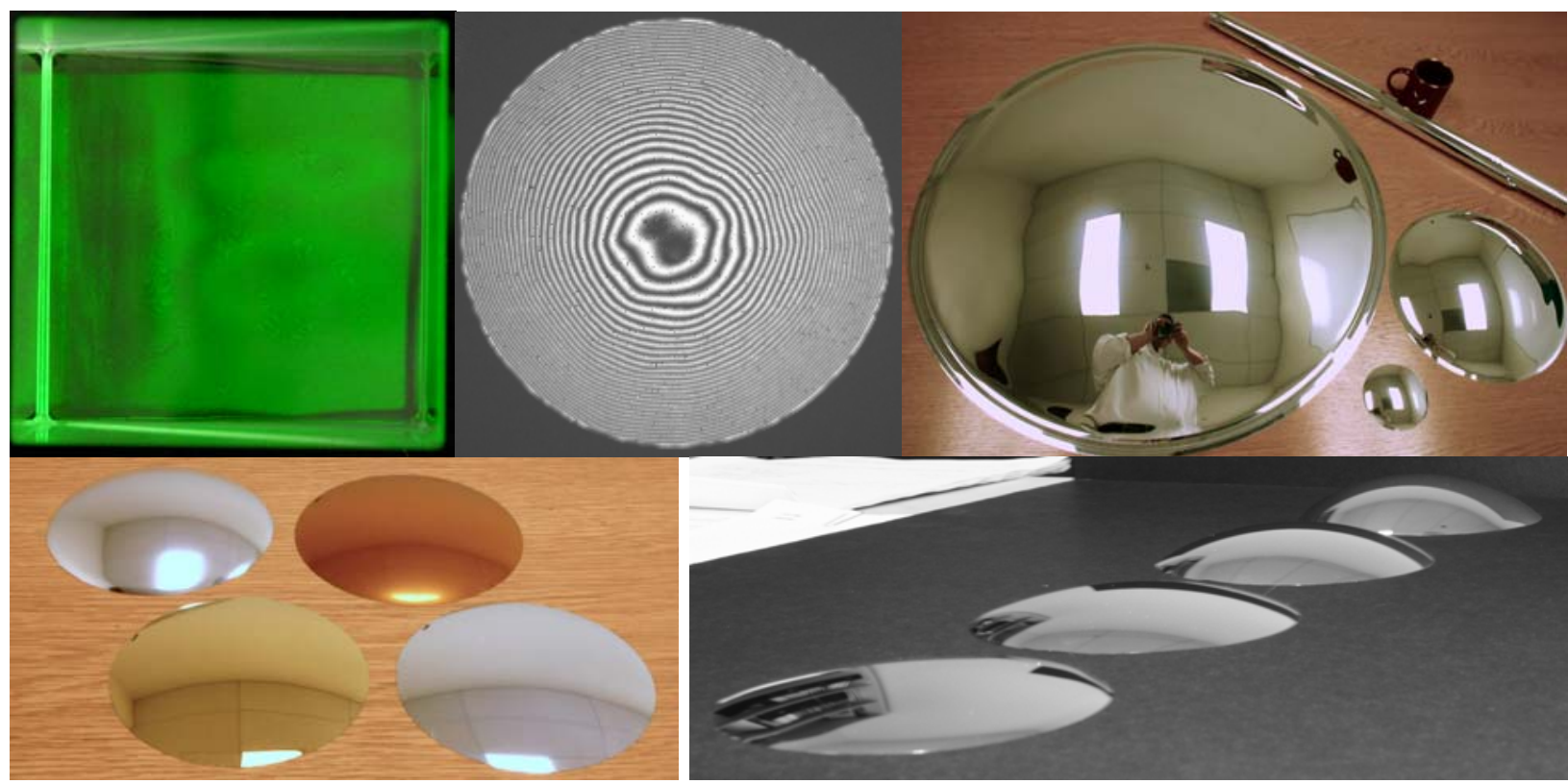

Figure 3: Summary of current state of the art for Membrane Aperture Shell Technology (MAST) fabrication: Row 1 (left to right): Minimal material thickness variation (green light self intereference), interferometric measurements of reflective powered surfaces ( $20 \mathrm{~nm}$ rms noise floor over 25 to $50 \mathrm{~mm}$ diameter sample areas), scalable fabrication process ( 0.1 to $0.75 \mathrm{~m}$ shells shown). Row 2 (left to right): Flexible fab process compatible with range of material coatings/finish and radius of curvature ( $R / 2.2$ to $R / 0.9$ shells made with same tooling).

Shells of this type are felt to exhibit several advantages that include 1) inherent structural stiffness, 2) compact roll (foldless) stowage, 3) deterministic passive self deployment and self rigidization, 4) dynamic stiffness, and 5) mass/component count advantages (no required tensioning, pressurization canopy, pressurization systems). These 
characteristics can make form stiffened shells attractive solutions for a range of space applications including solar concentrators, precision RF to optical apertures, and possibly non-precision surfaces that are traditionally realized with tensioned membrane flats (solar sails, thin film solar array substrates, sun shields, etc.). This particular paper is focused on recent results demonstrating performance traits suitable for enabling RF applications. In the remainder of this paper we discuss analytical and experimental work related to establishing that candidate materials offer the required sufficient conditions for good RF performance (i.e. low surface roughness and high RF reflectivity) and then review a series of experimental RF range tests demonstrating successful performance in the $\mathrm{S}$, $\mathrm{C}$, and KaBands.

\section{Material Characteristics Required for RF Performance}

In this section we discuss key requirements for good RF aperture performance (sufficient surface smoothness and high RF reflectivity) and demonstrate that the Membrane Apertures possess the required qualities.

\section{A. Surface Figure Requirements}

Much like in the optical domain, allowable departure of the actual RF surface roughness from the required surface can be cast in terms of ratio to the operational wavelength of interest. It can be shown ${ }^{1}$ that the RF gain knockdown ratio can be predicted by:

$$
\frac{G}{G_{0}}=e^{-x^{2}} \text { where } x=4 \pi \frac{\varepsilon}{\lambda}
$$

and where $\varepsilon$ is the figure error (as measured by rms error-surface in the same units as the operational wavelength, $\lambda$ ), and $G$ is the actual gain (in base $10 \mathrm{dBi}$ ) and $\mathrm{G}_{\mathrm{o}}$ is the nominal ideal gain for a reflector with no figure error from any source The resulting trends are shown in Figure 4 in $\mathrm{dB}$ and $\%$ mode. The typically accepted conclusion is that $\lambda / 30$ results in usually acceptably minor reduction in gain, and that $\lambda / 55$ is even more conservative. The allowable rms-surface error for different typical RF communication bands from 1 to $100 \mathrm{GHz}$ are summarized in Table 1. Surface roughness requirements thus stretch from $5.5 \mathrm{~mm} \mathrm{rms}$ at $1 \mathrm{GHz}$ at the low end of the L-band to $55 \mathrm{um} \mathrm{rms}$ at $100 \mathrm{GHz}$ at the high end of the W-Band.
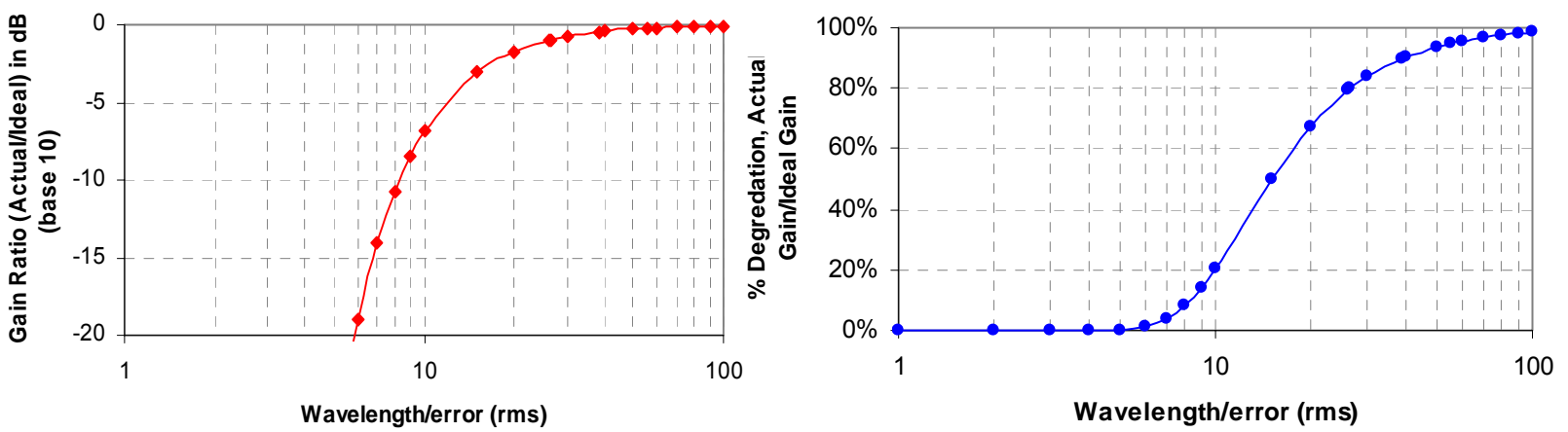

Figure 4: Effect of surface figure error on RF performance (both in dB-Gain mode (right) and \% mode, left)

As outlined above, candidate materials must exhibit suitable surface figure roughness in order to be a suitable RF reflector substrate. As will be shown in this section, multiple materials have been shown through optical interferometric measurements to offer more than sufficient smoothness. Most materials tested have surface figure errors of below $200 \mathrm{~nm}$ rms. The better materials trend towards $20 \mathrm{~nm}$ rms. A representative surface contour plot developed with Mevicon Inc.'s Wavefront Toolbox based on data extracted from the Zygo GPI MetroPro software for a candidate material with significant space flight heritage is shown on the left of Figure 5. Examination of the surface contours show that while the material exhibits a periodic ridge-trough feature (oriented mostly north south) and an underlying global variation. The results are more than sufficient for RF work, i.e. after removal of known test fixture boundary effects, the material exhibited a $132 \mathrm{~nm}$ rms surface roughness over the $80 \mathrm{~mm}$ diameter setting. This is more than 2 orders of magnitude better than required for RF operation in even the upper end of the W Band. These results were obtainable despite a somewhat diffuse reflective surface characteristic. Surface 
roughness trends for other previously characterized materials are also shown on the right of Figure 5. They generally show similar to better trends.

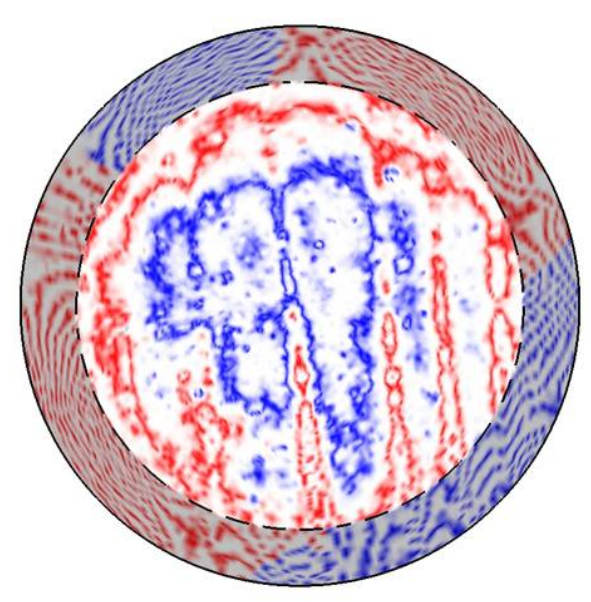

Test Initial, Ø $0.1 \mathrm{~m}$, Material 1

$\mathrm{RMS}=132 \mathrm{~nm}$

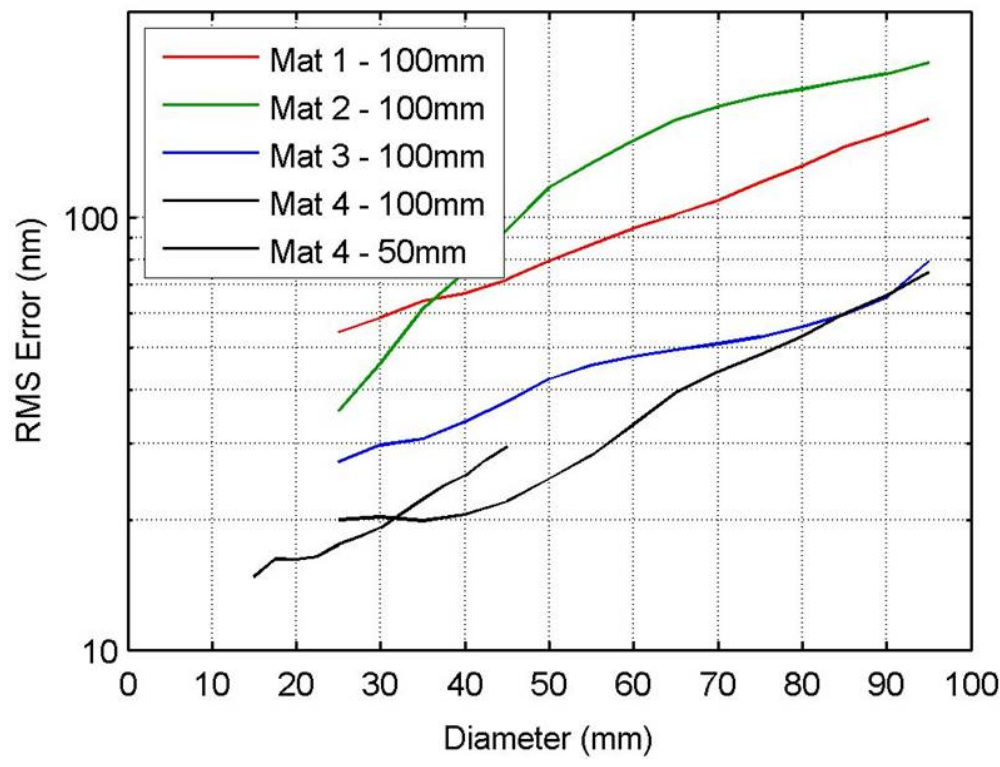

i $200 \mathrm{~nm}$, Ri-Ro 0\%-80\%

Figure 5: Example interferometric surface roughness measurement results for $100 \mathrm{~mm}$ diameter sample of candidate RF material (Material 1, red line on rms vs. diameter plot)

\section{B. Coating Thickness for RF Reflectivity}

In addition to having sufficient surface roughness, the substrate material must provide the proper RF reflectivity. Required metallic coating thickness is an important parameter in ensuring adequate RF performance. While calculations of skin depth are traditionally used to estimate the reflective material thickness required to achieve good reflectivity, it can be shown that skin depth is actually a measure of absorbtion, not reflection ${ }^{20}$. Thus it has been found to result in an overly conservative coating thickness results. Another way to solve for the required coating thickness to achieve suitable RF reflectivity is to relate the reflectivity to the conductivity of the coating material. With the conductivity, one can use the following equation, derived from Maxwell's equations, to relate the reflectivity, $\mathrm{r}$, to the conductivity, $\sigma$, the material's thickness, $\Delta$, and the impedance of free space, $\xi$.

$$
r=\left(\frac{\xi \sigma \Delta}{2+\xi \sigma \Delta}\right)^{2}
$$
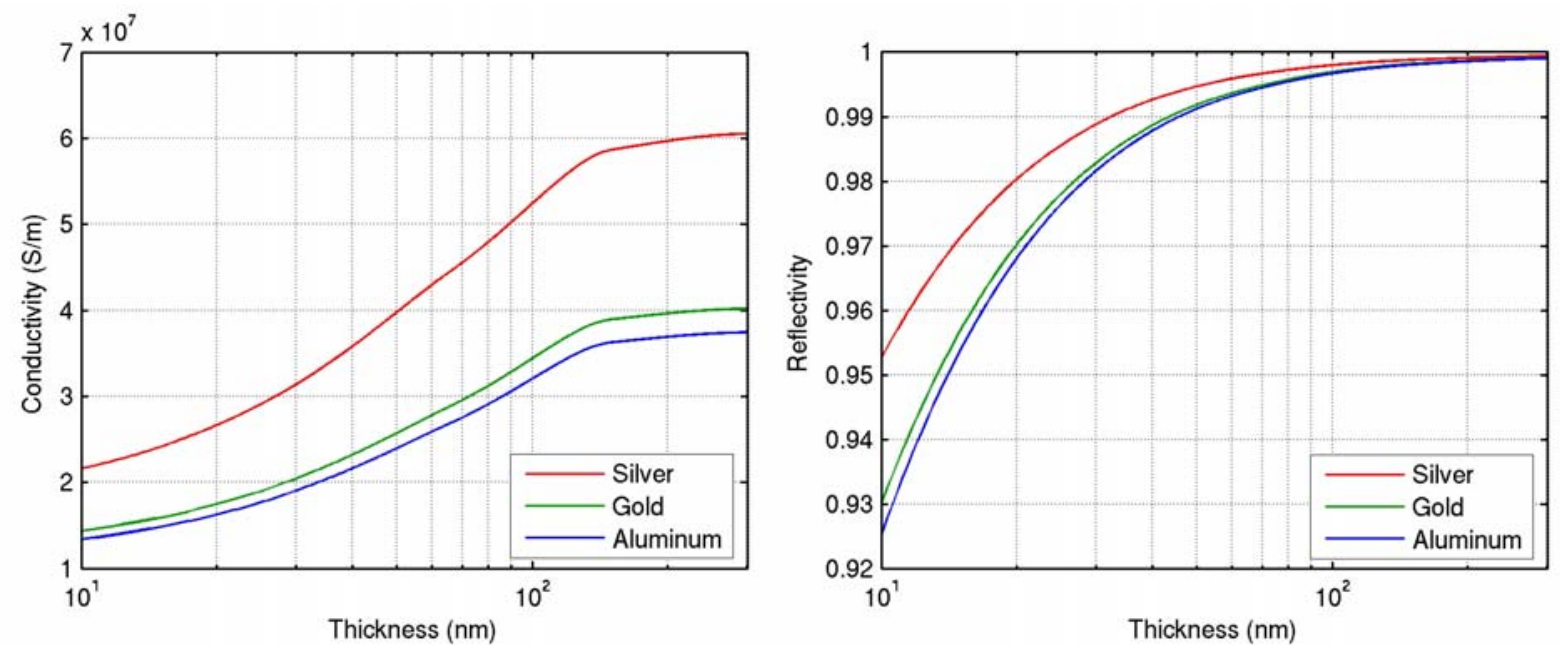

Figure 6: Conductivity, left, and reflectivity, right, versus coating thickness for silver, gold and aluminum at $1.4 \mathrm{GHz}$ (derived from Cravey \& Lawrence $^{21}$ ). 
When using the above equation, the material conductivity is typically derated from the bulk conductivity that is typically defined for a material whose thickness is at least 100 times thicker then an electron's mean free path. The left of Figure 6 gives the conductivity for several materials at different thicknesses at $1.4 \mathrm{GHz}^{21}$. As shown on the right of Figure 6, based on these values and the above approach the film's RF reflectivity can be extremely high even for very thin coatings. At $1.4 \mathrm{GHz}$, even a $10 \mathrm{~nm}$ thick aluminum coating yields $90 \%+$ reflectivity. $50 \mathrm{~nm}$ thick coatings yield $99 \%+$ reflectivity for all considered metals. These results have been borne out experimentally as described in the following section. While not derived here, required RF coating thickness can generally be expected to decrease with increasing operating frequency as the associated wavelength decreases.
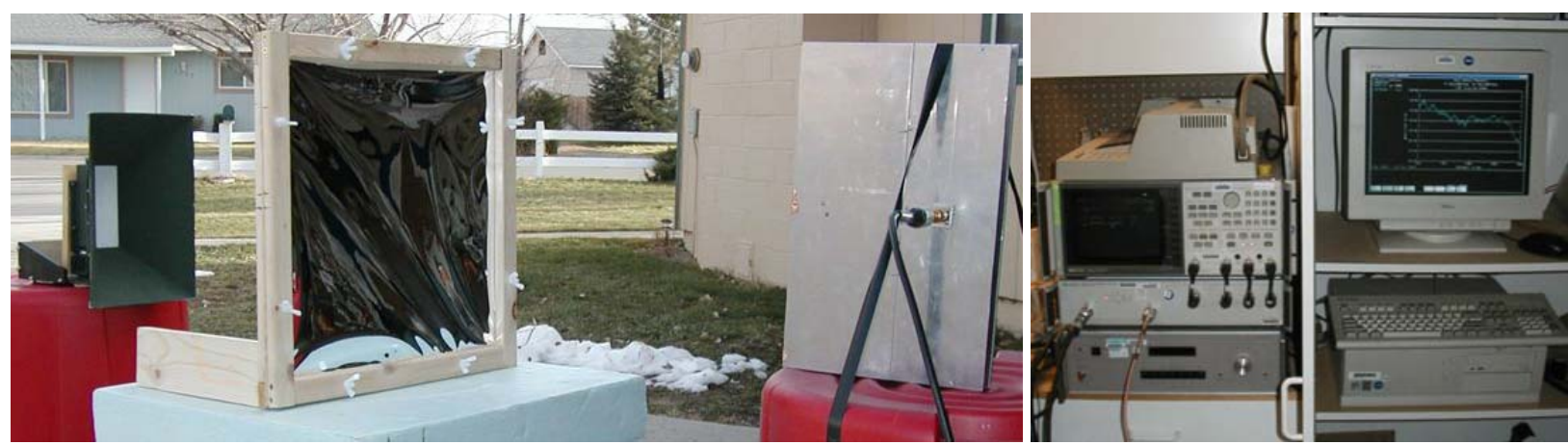

Figure 7: Test setup (emitter feed horn (left), sample under test (middle), and receiver antenna (right)) and computer controlled network analyzer used for RF measurements

In order to confirm the above numerical results prior to initiating full aperture tests, transmission/reflection measurements ${ }^{22}$ were made on a range of coated and uncoated candidate materials were performed over a frequency range of 1 to $3 \mathrm{GHz}$ using the free space transmission method. Both coated and uncoated samples were tested. For comparison purposes, tests were also performed with no material in the frame and tests with a relatively thick (1/32") aluminum plate in the frame. The measurements were performed outdoors to minimize spurious sources of reflections. All measurements were performed using a computer-controlled HP network analyzer shown on the right of Figure 7, which sampled 400 equal increments across the frequency band. Results of these measurements are plotted and described below. As shown on the left of Figure 7, two horn-type antennas were placed facing one another with the sample in between. A 20-inch square wooden frame was used to hold the sample roughly flat at right angles to the centerline of the horns. Wrinkle amplitude was judged not high enough to materially effect these S-Band measurements. Spacing from each horn aperture to the sample was 28 inches. Results (Figure 8) were generally found to agree quite well with expectations. Coated materials were very RF reflective, and non coated materials were very RF transmissive, i.e. the uncoated polyester and polyimide samples had the same signature as the bare test frame, and the 100 to $200 \mathrm{~nm}$ thick coated samples had the same signature as the 800 um thick aluminum plate sample.
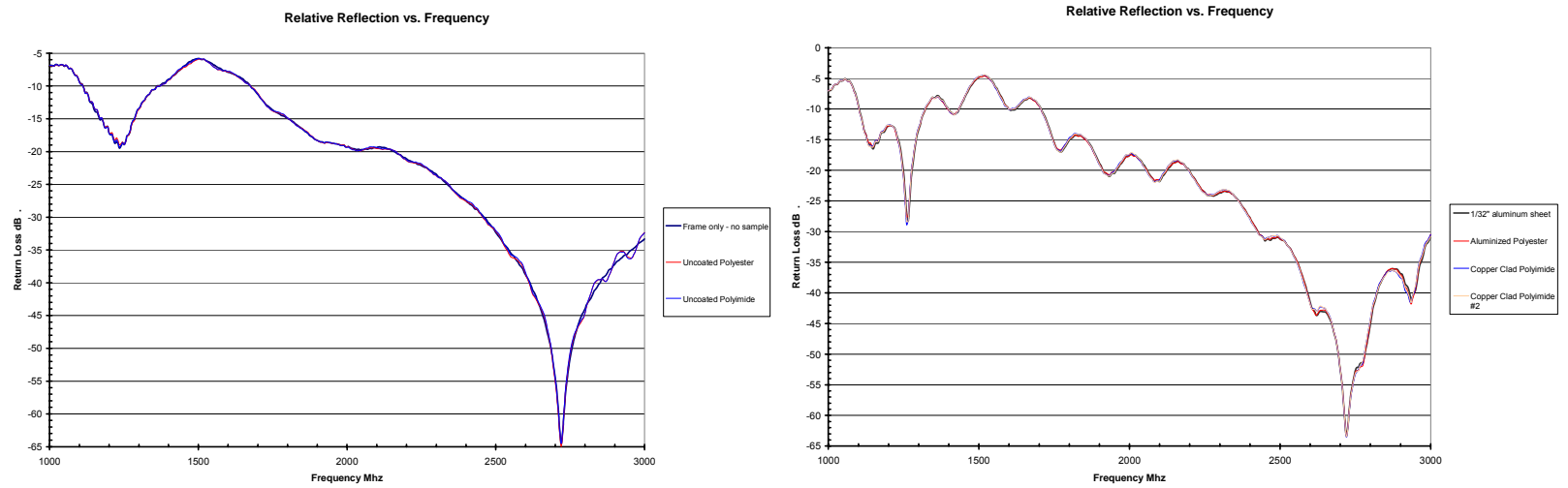

Figure 8: Relative reflection measurements

Left: Non coated polyester and polyimide samples (results identical to baseline empty frame) Right: Coated polyester and polyimide samples (results identical to baseline aluminum sheet) 


\section{Aperture Level RF Performance Demonstrations}

Building on the above positive results, a wide range of doubly curved aperture configurations were fabricated and subjected to RF testing, from the $\mathrm{S}$ to the Ka Band. The configurations discussed in this paper are summarized in Figure 9. Upcoming test campaigns are expected to yield results at higher frequency and at larger aperture sizes. Prior to discussing the experimental results, we provide some background on estimating expected performance and then reviewing the RF test range set up. This is followed by results from S-Band, C-Band, Ka-Band measurements of single surface shells, as well as results from an early S-Band test of a segmented aperture.

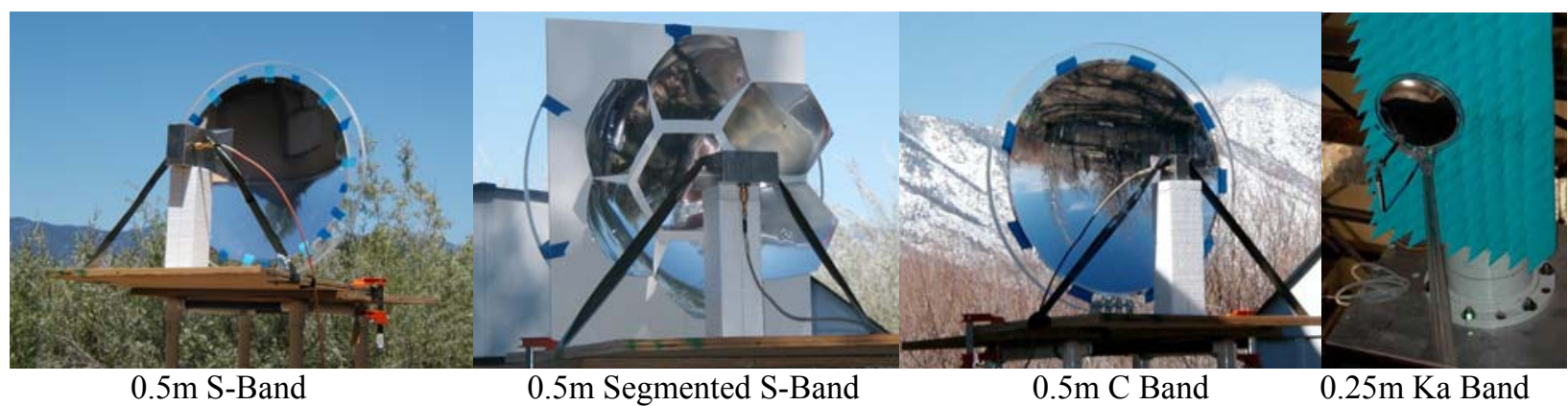

Figure 9: Overview of tested RF aperture configurations

\section{A. Analytically Expected Performance}

The theoretical gain of an aperture type antenna can be written as:

$$
\left.\mathrm{G}=10 \log _{10}\left(\eta 4 \pi \mathrm{A} / \lambda^{2}\right) \quad \text { or in terms of aperture diameter } \quad \mathrm{G}=10 \log _{10}\left(\eta\left(\pi^{2} \mathrm{D}^{2}\right) / \lambda^{2}\right)\right)
$$

where $\mathrm{G}$ is gain in $\mathrm{dBi}, \eta$ is the efficiency, $A$ is the aperture area, and $\lambda$ is wavelength. With gain measured, one can typically 'back out' the system efficiency, $\eta$, which is used to capture the effects of various degrading factors such as the already discussed material surface roughness, surface figure errors, low number of waves across the aperture, any feed effects such as blockage, etc. Total system efficiencies of better than $50 \%$ are typically considered acceptable. Another measure of antenna performance is how well the 3-dB or half-power beamwidth compares with theory. The theoretical beamwidth of an aperture type antenna is given approximately by the following formula:

$$
\mathrm{HPBW}=70 \lambda / \mathrm{D}
$$

where HPBW is the half-power beamwidth in degrees, $\lambda$ is wavelength, and $\mathrm{D}$ is the aperture diameter. This can generally be extracted directly from experimental measurements with less sensitivity to gain standard calibration. While this metric does not include the efficiency factor of effects such as feed tailoring, it also is quite useful.

\section{B. Test Set Up Overview}

Antenna radiation patterns were measured for the reflector and feed combination on an outdoor range using the same equipment setup shown on the right of Figure 7. A range length of $4.88 \mathrm{~m}$ ( 16 feet) was used due to the limits of the test range. For S-Band tests, this meets the accepted practice of testing at a minimum far-field distance of $2 D^{2} / \lambda$, where $D$ is the aperture diameter and $\lambda$ is the RF wavelength at the highest test frequency. While the measurements were made with the antenna under test in the receive mode, the resulting antenna patterns apply equally to the transmit mode due to reciprocity. The RF levels were compared with a known level established using a calibrated standard gain horn, resulting in radiation patterns measured in $\mathrm{dB}$ relative to isotropic, or $\mathrm{dBi}$. Patterns were measured with the transmit antenna and feed horns both polarized vertically, resulting in a magnetic field or $\mathrm{H}-$ plane cut. Then both the transmit antenna and the feed horn were turned to the horizontally polarized position and an electric field or E-plane cut was measured. In general, RF transmissive support structures were used to hold the feed and support the entire assembly in order to mitigate spurious RF reflections from test support equipment.

\section{Example 0.5m On-Axis S-Band (2-3GHz) Performance}

A $0.5 \mathrm{~m}$ diameter, $\mathrm{R} / 1.12$ membrane shell made from the space grade aluminized material $(100 \mathrm{~nm}$ thick aluminum coating, 125 um thick substrate, $175 \mathrm{~g} / \mathrm{m}^{2}$ surface film areal density), was fabricated at Mevicon, shipped (roll stowed) to the Neveda Test Range, installed on an RF transmissive support structure, and S-band tested (from 2 to $3 \mathrm{GHz}$ or $\lambda=150$ to $100 \mathrm{~mm}$ ) in prime focus mode. An RF feedhorn was designed to yield optimal balance of aperture illumination to achieve an acceptable balance between maximum gain with minimized sidelobes. Feed pattern was down approximately $10 \mathrm{dBi}$ by edge of the shell. A series of RF measurements were taken from 2 to 3 
$\mathrm{GHz}$ over a range of orientations (receiver rotated). Example measured $\mathrm{E}$ and $\mathrm{H}$ antenna patterns are shown in the polar plots shown below (Figure 10). Despite being electrically small (i.e. diameter is only 3 to $5 \lambda$ ), the reflector yields good performance, better than $22 \mathrm{dBi}$ at $3 \mathrm{GHz}$. Side lobe levels were elevated by the relatively large feedhorn blockage and test range effects. Efficiency tended to vary from 40 to $60 \%$ over the test frequency range (Figure 11). Variability is currently attributed to variation in feedhorn behavior over that frequency range. HPBW was uniformly lower than calculated, showing good overall performance.

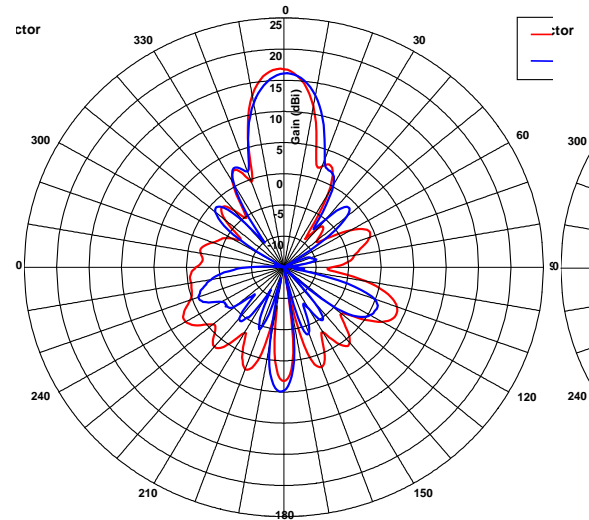

$2 \mathrm{GHz}$

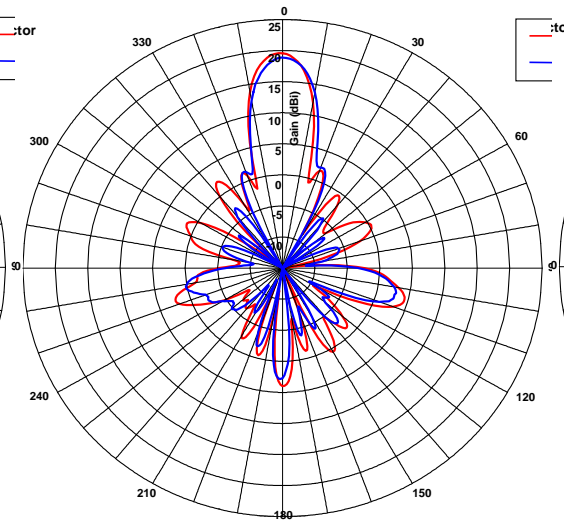

$2.5 \mathrm{GHz}$

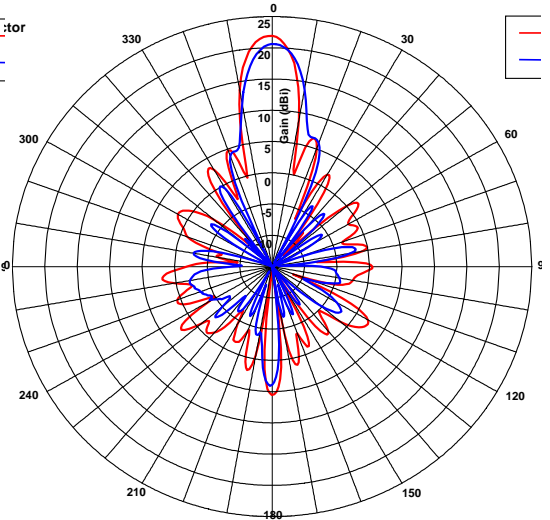

$3 \mathrm{GHz}$

Figure 10: Measured primary and side lobe gain profile for experimental $0.5 \mathrm{~m}$ shell (plotted as $\mathrm{dBi}$ )
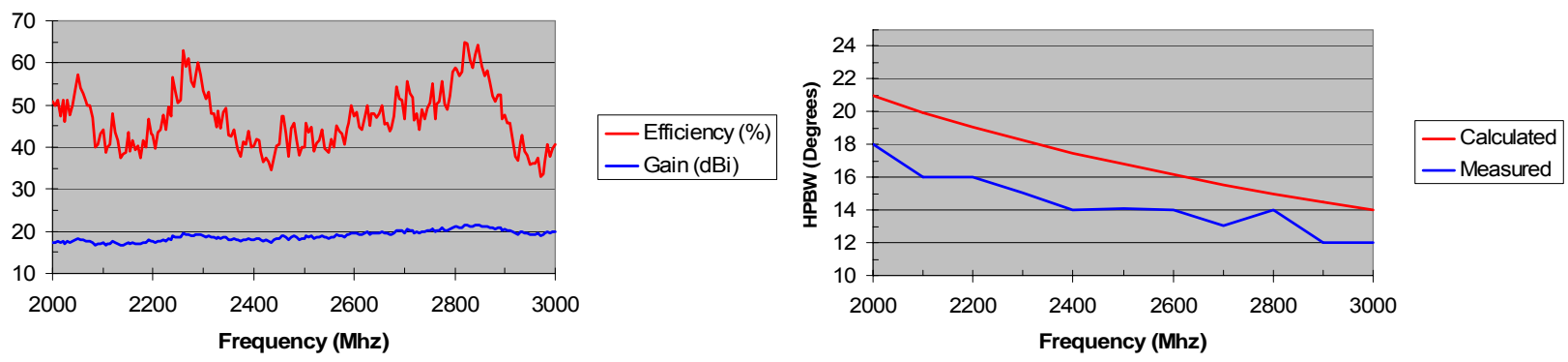

Figure 11: 2 to $3 \mathrm{GHz}$ gain, efficiency, and half power beamwidth measurements

\section{C-Band (4 to 6 GHz) 0.5m On-Axis Demonstration}

Building on the above results, we subsequently tested a similar $0.5 \mathrm{~m}$ on axis reflector in the C-Band for its performance over 4 to $6 \mathrm{GHz}(\lambda=75$ to $50 \mathrm{~mm})$ in $200 \mathrm{MHz}$ steps. Overall results were quite good as shown in Figure 12. Gains ranging from 25 to $28 \mathrm{dBi}$ were observed, yielding very respectable calculated system efficiencies starting at 80 to $90 \%$ and slowly dropping towards $50 \%$ as frequency increased. This is not unexpected as the feedhorn design/illumination design was optimized in the $4 \mathrm{GHz}$ range and illumination fill factor starts to drop as frequency increases. Relative to the S-Band tests, part of the reasons for the improved performance is the larger effective aperture electrical size, 6.6 to 10 waves (versus 3.3 to 5), and the proportionally smaller feedhorn. As each feedhorn dimension is essential a factor of 2 smaller, the on-axis prime focus area blockage effect is down by a factor of 4. Most efficient operation was at $4.6 \mathrm{GHz}$ and polar coordinate plots of $\mathrm{E}$ and $\mathrm{H}$ plane measurements are shown in Figure 13.
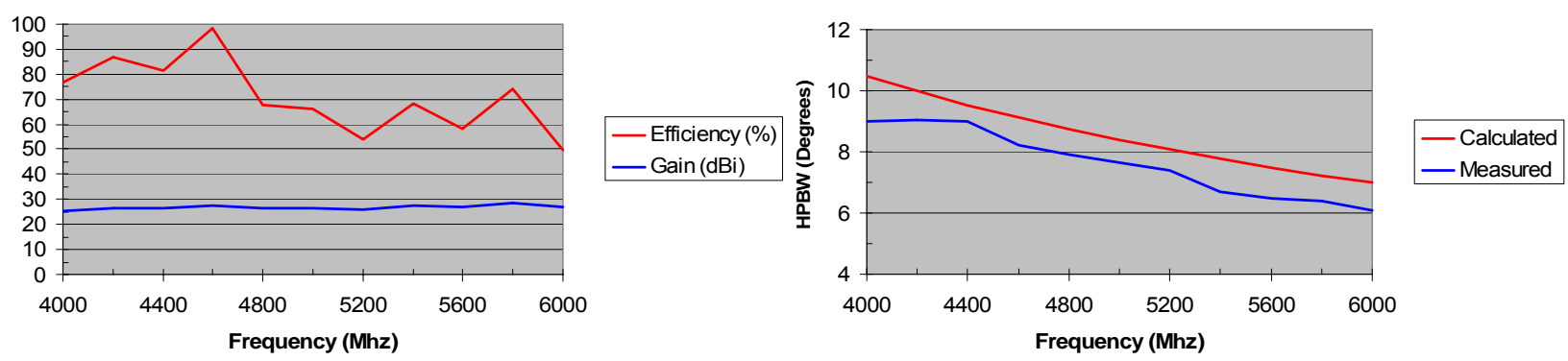

Figure 12: 4 to $6 \mathrm{GHz}$ test measurement results 
In general, performance was quite excellent with very low side lobe levels. The exceptions to this, such as the well defined asymmetric sidelobe spike in the gain plots near $300 \mathrm{deg}$, is attributed to spurious reflections from the antenna feedline, and the larger asymmetric lobe at $240 \mathrm{deg}$. is attributed to a test range artifact (spurious reflection off distant metal object in antenna field of view).

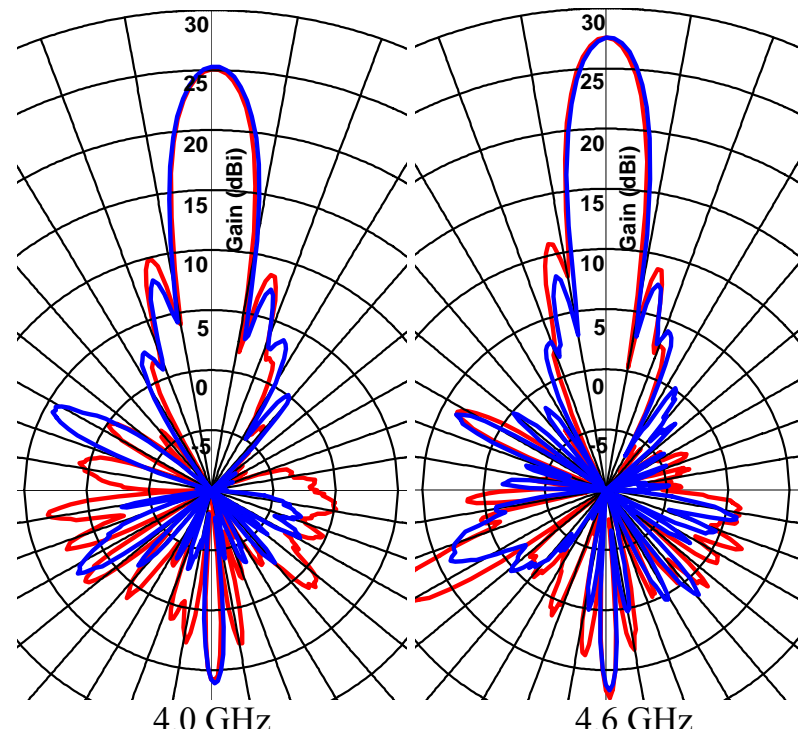

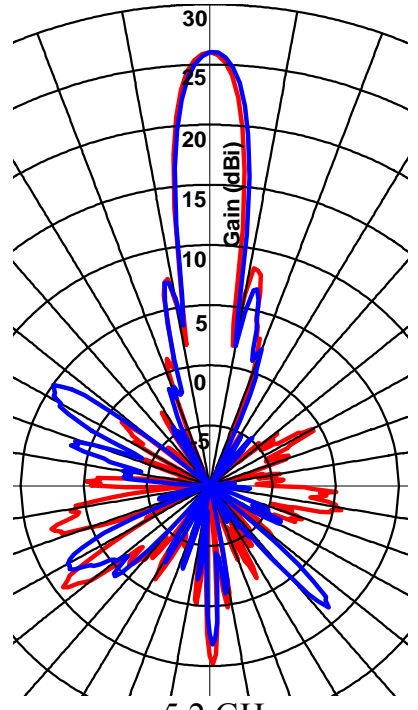

$5.2 \mathrm{GHz}$

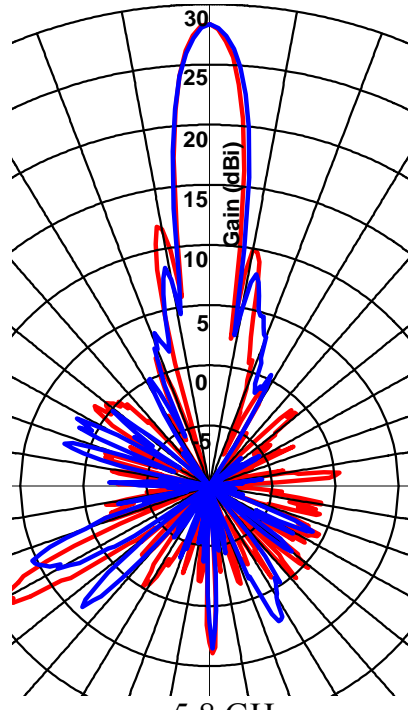

$5.8 \mathrm{GHz}$

Figure 13: Example C-Band (4.0 to 5.8 GHz) polar gain plots.

\section{E. 32 GHz (Ka-Band) RF Test Results}

Additionally, a $0.25 \mathrm{~m}$ diameter on-axis shell from space heritage material (5 mil polyester with a $100 \mathrm{~nm}$ aluminum single sided coating) has been successfully RF tested in the Ka-Band (at $32 \mathrm{GHz}, \lambda=9.4 \mathrm{~mm}$ ) at NASA Glenn Research Center (NASA-GRC). Aperture prescription was an on axis F/0.56 shell. The $0.25 \mathrm{~m}$ diameter shell was initially simply attached at four locations to an RF transparent frame but best results were attained for a center only mount configuration. Projected dot photogrammetry measurements ${ }^{23}$ made by Mevicon agreed reasonably well with laser radar scanner measurements made by NASA-GRC personnel with surface figure measured to be between 200 to $400 \mu \mathrm{m}$ rms-surface over the full aperture (significantly better over the inner regions) for this prototype shell. The measured surface profile was used to calculate the predicted antenna gain and side lobe levels at $32 \mathrm{GHz}$. The shell and numerically predicted antenna gain pattern is shown in Figure 14.
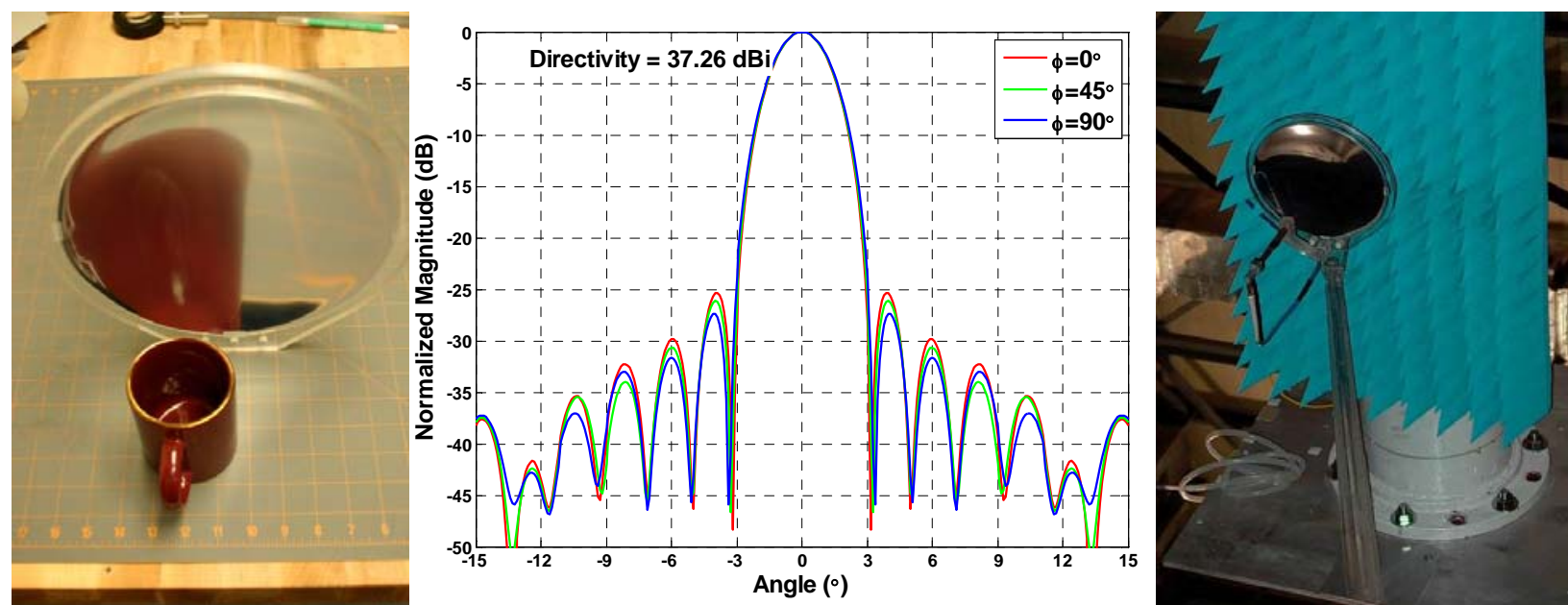

Figure 14: Predicted antenna performance based on laser radar surface measurements (left) and experimental $0.25 \mathrm{~m}$ shell prior to shipment (right)

Test shell aperture size was initially chosen so that it could be tested in the NASA-GRC far field test range. Scheduling conflicts however led it to be tested in the near field test range. It was also initially planned to perform tests in the X-band (at $8.4 \mathrm{GHz}, \lambda=35.7 \mathrm{~mm}$ ), but based on the excellent laser radar surface figure measurements, 
NASA-GRC personnel decided to proceed directly to the Ka-Band (32 GHz). They prototyped a stand and $32 \mathrm{GHz}$ prime focus feed (matched to the F/0.56 prescription) and installed it in the near field test range. As this is likely the smallest shell ever tested in that range (it is capable of testing up to $4.5 \mathrm{~m}$ apertures) some quick RF shielding (i.e. the foam core) was required to be installed to block spurious reflections from test chamber objects that are normally 'concealed' behind larger antennas under test. As noted above, the laser radar measured surface figure was used to generate predictions of the expected gain pattern with a predicted maximum gain of $37.26 \mathrm{dBi}$. Nominal feedhorn effects were included in the model. While there was reasonable agreement on the main-lobe, side lobe levels were generally higher than expected, especially for the horizontal cut. After an initial test, the shell was thus removed from its original four point mounting and remounted at a single point in its middle. This configuration was then recharacterized. The resulting improved gain pattern results are summarized in Figure 15 along with the phase hologram (The large feature in the middle of the phase hologram is the shadow of the on-axis feed horn and feed line). While the horizontal cut results still show high side lobe levels, zero locations are better defined for both measurements. Peak gain of $36.8 \mathrm{dBi}$ was measured, which compares well versus to the predicted directivity of $37.26 \mathrm{dBi}$. Overall system efficiency is $68 \%$.
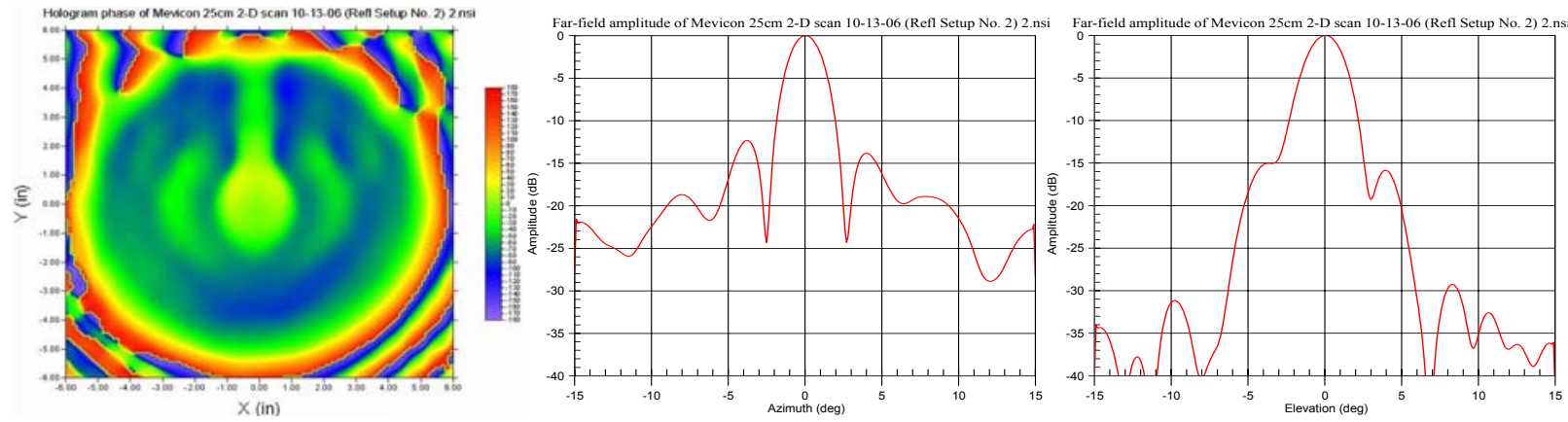

Figure 15: Phase hologram, vertical and horizontal slices for $32 \mathrm{GHz}$ RF measurements of $0.25 \mathrm{~m}$ shell in its second boundary. Peak gain of $36.8 \mathrm{dBi}$ was attained which is equivalent to $68 \%$ antenna efficiency.

\section{F. Segmented Aperture S-Band RF Demonstration}

Leveraging our work towards using segmentation as a path towards scaling to larger apertures from convenient building blocks ${ }^{24}$, a segmented hexagon system was built for purposes of performing quick RF tests to confirm performance. Such tests were felt important as there had been some questions as to whether a segmented RF aperture would act like continuous shell it approximated or more like a summary of disparate parts. The former was suspected to be the case based on analogy to segmented optical systems and also the fact that an RF system often has multiple physically separate reflectors (i.e primary and secondary, etc.) However, no explicit confirmation in the literature could be found. The goal of these measurements was thus to measure gain patterns and to compare antenna patterns for a segmented reflector shape with earlier antenna patterns for the most similar solid reflector shape.
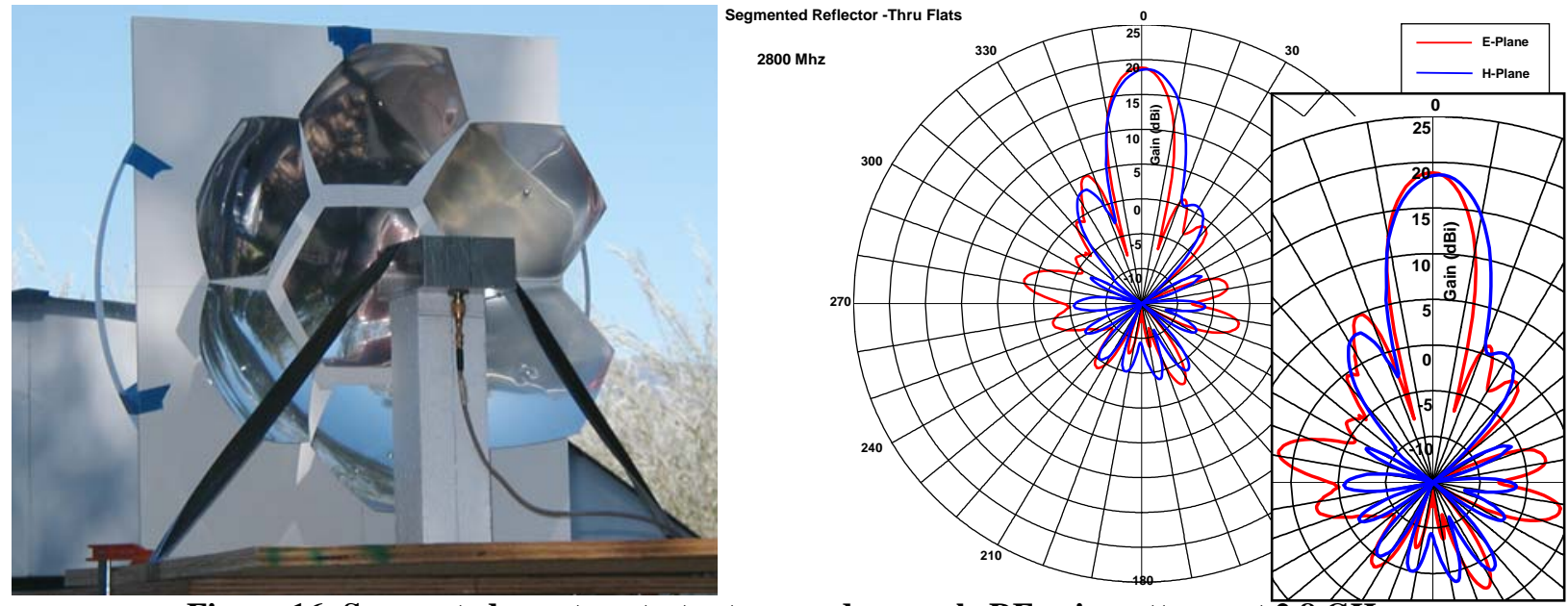

Figure 16: Segmented aperture test set up, and example RF gain patterns at $2.8 \mathrm{GHz}$. 
The segmented reflector is made up of seven hexagonal segments as shown on the left of Figure 16. Each segment was $0.2 \mathrm{~m}$ corner to corner, has nearly an identical radius of curvature and thus could be combined to for a spherical aperture. Both reflectors have an approximate aperture diameter of $0.5 \mathrm{~m}$, and the $\mathrm{F} \#$ for the segmented shape is fast at F/0.3 while that of the solid shape is slower at F/0.541. Since the segmented reflector has a faster F\#, and therefore a wider intercept angle from the feed, the flare was removed from the feedhorn in order to broaden the feed pattern for the segmented reflector measurements. These differences in feed behavior will influence the comparative results. Setup and procedure for the segmented reflector shape measurements were identical to those used to characterize the solid reflectors. An example radiation patterns of the segmented reflector at $2.8 \mathrm{GHz}$ is shown on the right of Figure 16. The segmented and the solid reflectors have fairly similar antenna patterns in the 2-3 GHz frequency range. However, there are some differences in gain, beamwidths, and sidelobe levels as explained below.

- The gain for the segmented reflector is lower than that of the solid reflector by 1-3 dB across the frequency band. This is probably due to a combination of: 1) surface errors in the segments (there was some droop at the edges of the segments due to gravity when the reflector was in its upright test position), 2) gaps between the segments, which probably reduce the effective aperture area, and 3) under-illumination in the H-plane, which contributes to a reduction in the aperture efficiency.

- The H-plane beamwidth is broader across the frequency band for the segmented reflector. This is most likely due to the feed induced under-illumination in the H-plane that was noted earlier.

- The segmented reflector has higher sidelobes, particularly in the E-plane, and particularly in the lower frequency ranges. This is probably caused by surface errors in the implementation of segments to form the reflector, and is not as prevalent in the H-plane due to the under-illumination in that plane.

\section{G. Summary}

The RF performance of MAST single surface membrane apertures were RF tested in the S, C, and Ka-Bands (2to $3 \mathrm{GHz}, 4$ to $6 \mathrm{GHz}$, and $32 \mathrm{GHz}$ ) with good system efficiency metrics. Summary results are provided in Table 2. With refinement of feedhorn/feedpattern matching and transitioning to off-axis configurations, further increases in efficiency (and hence peak gain) can be expected. The ability of MAST single surface membrane shells to functionally operate similar to more traditional RF apertures despite having metallic coatings much thinner than the typically considered minimum skin depths thickness has been demonstrated.

Table 2: Summary of RF Performance Demonstrations

\begin{tabular}{|c|c|c|c|c|c|c|l|}
\hline $\begin{array}{c}\text { RF } \\
\text { Band }\end{array}$ & $\begin{array}{c}\text { Freq } \\
(\mathrm{GHz})\end{array}$ & $\begin{array}{c}\text { OD } \\
(\mathrm{m})\end{array}$ & F\# & $\begin{array}{c}\text { Peak } \\
\text { Gain }\end{array}$ & $\begin{array}{c}\text { HPBW } \\
\text { (deg) }\end{array}$ & $\begin{array}{l}\text { Best Sys. } \\
\text { Efficiency }\end{array}$ & $\begin{array}{l}\text { Test } \\
\text { Location }\end{array}$ \\
\hline $\mathrm{S}$ & $2-3$ & 0.50 & 0.541 & $22 \mathrm{dBi}$ & $18-12$ & 35 to $65 \%$ & NTR \\
\hline $\mathrm{C}$ & $4-6$ & 0.50 & 0.541 & $28 \mathrm{dBi}$ & 9 to 6 & 50 to $90 \%$ & NTR \\
\hline $\mathrm{Ka}$ & 32 & 0.25 & 0.56 & $36.8 \mathrm{dBi}$ & 2.4 & $68 \%$ & GRC \\
\hline & & & & & & & \\
\hline $\mathrm{S}$ & $2-3$ & 0.45 & 0.3 & $\approx 18 \mathrm{dBi}$ & $23-15$ & $\approx 35 \%$ & NTR \\
\hline
\end{tabular}

\section{Summary}

This paper provides an overview of recent results establishing the suitability of Membrane Aperture Shell Technology (MAST) as passive reflective dish component for Radio Frequency (RF) applications. These single surface shells are capable of maintaining their figure with no preload or pressurization and minimal boundary support, yet can be compactly roll stowed and passively self deploy. As such, they are a promising technology for enabling a future generation of RF apertures. A numerical justification for using a reflectivity metric, as opposed to the more standard RF designer metric of skin depth, is presented and is experimentally validated with material sample tests. The validity of these independent film sample measurements are then confirmed through experimental results demonstrating RF performance for reasonable sized doubly curved apertures. Currently available best results are $22 \mathrm{dBi}$ gain at $3 \mathrm{GHz}$ (S-Band) for a $0.5 \mathrm{~m}$ aperture tested in prime focus mode, $28 \mathrm{dBi}$ gain for the same antenna in the $\mathrm{C}$-Band (4 to $6 \mathrm{GHz}$ ), and $36.8 \mathrm{dBi}$ for a smaller $0.25 \mathrm{~m}$ antenna tested at $32 \mathrm{GHz}$ in the Ka-Band. RF range test results for a segmented aperture (one possible scaling approach) are shown as well. Measured antenna system actual efficiencies (relative to the system with an ideal isotropic source) for these on axis tests are generally quite good, typically ranging from 50 to $90 \%$. Key results of this paper is the experimental confirmation that 1) the typically referenced skin depth calculations for reflective coating thickness are overly conservative, and 2) that MAST shells function like traditional RF apertures (at least for $\mathrm{S}$ to $\mathrm{Ka}$ band, although there is no reason for 
performance to not continue well into the $\mathrm{W}$ band) and can thus be designed using similar design rules as developed for traditional aperture approaches. Future work is expected to look at demonstrating performance at higher frequencies, and larger aperture diameters.

\section{References}

1 Richard C. Johnson, 1993, Antenna Engineering Handbook, Third Edition, McGraw-Hill.

2 Mark Thomson, 1998, "The AstroMech Deployable Reflector", International Union of Theoretical and Applied Mechanics IASS Symposium on Deployable Structures: Theory and Applications, September.

3 Donald C. Elder, 1995, Out From Behind the Eight-Ball: A History of Project Echo, AAS History Series, Vol. 16.

4 Christopher H. M. Jenkins, Ed., 2001, Gossamer Spacecraft: Membrane and Inflatable Structures Technology for Space Applications, Vol. 191, AIAA Progress in Astronautics and Aeronautics, AIAA Press, Reston Virginia.

5 J. Huang, M. Lou, A. Feria, Y. Kim, 1998, “An Inflatable L-Band Microstrip SAR Array”, Inst. of Electrical and Electronics Engineers AP-S/URSI Symposium Digest, pages 2100-2103, 1998

6 H. Fang, J. Huang, and U. Quijano; K. Knarr, J. Pzerez, L. Hsia, 2006, "Design and Technologies Development for an EightMeter Inflatable Reflectarray Antenna”, Paper\# AIAA-2006-2230, $7^{\text {th }}$ Annual Gossamer Spacecraft Forum, Newport, RI, May.

7 M.C. Bailey, T.G. Campbell, D. Brandt, C. Cassapakis, 1998, "Inflatable Tensioned Membrane Waveguide Antenna Array for Space Applications", IASS Symposium, September 1998

8 David Lichodziejewski, R. Cravey, G. Hopkins, 2003, "Inflatably Deployed Membrane Waveguide Array Antenna for Space" Paper \# AIAA-2003-1649, $4^{\text {th }}$ Annual Gossamer Spacecraft Forum, Norfolk, VA, April.

9 J. Lin, G. Sapna and S. Scarborough, B. Lopez, 2003, "Advanced Precipitation Radar Antenna Singly Curved Parabolic Antenna Reflector Development”, AIAA-2003-1651, $3^{\text {rd }}$ Annual Gossamer Spacecraft Forum, Norfolk, VA, April.

${ }^{10}$ Jason Tolomeo, Jay Loane, Domenick J. Tenerelli, Eugene W. Cross, Jr., William W. Sable, Tom Decker, Kin Chan, Tom Nelson, Bill Joseph, Connor Windes, Doug Kokawa, Alex Kamis, Mark Dragovan, Jennifer A. Dooley, 2004, "Design and test of a $2 \mathrm{~m} \times 4 \mathrm{~m}$ DART system in the RF" Proceedings of SPIE -- Volume 5166: UV/Optical/IR Space Telescopes: Innovative Technologies and Concepts, January 2004, pp. 124-130.

${ }^{11}$ Leland Bowen, Everett Farr, 2002, "Fabrication and Testing of a Membrane IRA", Sensor and Simulation Notes. \# 464 . Jan.

${ }^{12}$ R.E. Freeland, G.D. Bilyeu, G.R. Veal, 1997, "Large Inflatable Deployable Antenna Flight Experiment Results, 97-1.3.01, International Astronautical Federation, October.

${ }^{13}$ David Lichodziejewski, Costas Cassapakis, 1999, "Inflatable Power Antenna Technology" Paper \# AIAA-1999-1074, 37 AIAA Aerospace Sciences Meeting and Exhibit, Reno, NV, Jan.

${ }^{14}$ M.C. Bernasconi, E. Pagana, and G.G. Reibaldi, 1987, "Large Inflatable, Space Rigidized Antenna Reflectors: Land Mobile Services Development, IAF-87-315, International Astronautical Congress.

${ }^{15}$ J. Lin, H. Fang, E. Im and U. Quijano, 2006, "Concept Study of a 35-m Spherical Reflector System for NEXRAD in Space Application”, Paper \#AIAA-2006-1604, $7^{\text {th }}$ Annual Gossamer Spacecraft Forum, Newport, RI, May.

${ }^{16}$ James C. Pearson, Jr., Dr. Robert R. Romanofsky, 2006, “Thin Film Antenna Development and Optimization” Paper \# AIAA 2006-2229, $7^{\text {th }}$ Annual Gossamer Spacecraft Forum, Newport, RI, May.

${ }^{17}$ S. Chodimella, J. Moore and J. Otto, H. Fang, 2006, "Design Evaluation of a Large Aperture Deployable Antenna"AIAA2006-1603, $7^{\text {th }}$ Annual Gossamer Spacecraft Forum, Newport, RI, May.

${ }^{18}$ Michael C. Lou, John Huang, V. Alfonso Feria, 2001, "Radar Applications”, Chapter 16, Gossamer Spacecraft: Membrane and Inflatable Structures Technology for Space Applications, Vol. 191, AIAA Progress in Astronautics and Aeronautics, AIAA Press, Christopher H. M. Jenkins, Ed., Reston Virginia

${ }^{19}$ Eric M. Flint, Jason Lindler, Jonathan Hall, Charles Rankin, Marc E. Regelbrugge, 2006, "Overview of Form Stiffened Thin Film Shell Characteristic Behavior", Paper\#AIAA-2006-1900, $7^{\text {th }}$ Annual Gossamer Spacecraft Forum, Newport, RI, May.

${ }^{20}$ Constantine Balanis, 1989, Advanced Engineering Electromagnetics, John Wiley and Sons, Inc.

${ }^{21}$ R.L. Cravey, R.W. Lawrence, 2001, "Electromagnetic Properties of Thin Metallized Materials", Chapter 10, Gossamer Spacecraft: Membrane and Inflatable Structures Technology for Space Applications, Vol. 191, AIAA Progress in Astronautics and Aeronautics, AIAA Press, Christopher H. M. Jenkins, Ed., Reston Virginia

22 R.W. Lawrence, R.L. Cravey, 2001, "Electromagnetic Testing of Thin Metallized Materials", Chapter 13, Gossamer Spacecraft: Membrane and Inflatable Structures Technology for Space Applications, Vol. 191, AIAA Progress in Astronautics and Aeronautics, AIAA Press, Christopher H. M. Jenkins, Ed., Reston Virginia

${ }^{23}$ Eric M. Flint, Jason E. Lindler, Jonathan L. Hall, 2006, "Experimental Validation of Close-Range Photogrammetric Measurement Performance of Doubly Curved Surfaces", Paper \# AIAA-2006-1804. $7^{\text {th }}$ Annual Gossamer Spacecraft Forum, Newport, Rhode Island, May 1-5.

${ }^{24}$ Eric M. Flint, Jason E. Lindler, 2007, "Self Supporting Hexagon Shaped Membrane Aperture Thin Film Shells", Paper\# AIAA-2007-1841, $8^{\text {th }}$ Annual Gossamer Spacecraft Forum, Waikiki, HI, April. 


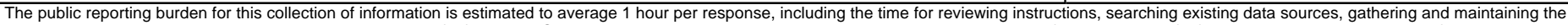

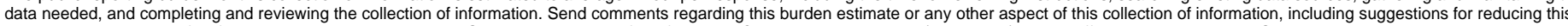

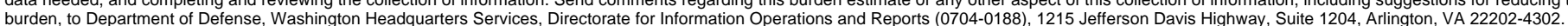

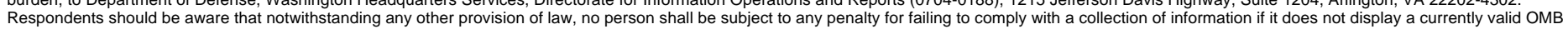
control number.

PLEASE DO NOT RETURN YOUR FORM TO THE ABOVE ADDRESS.

\begin{tabular}{l|l|l} 
1. REPORT DATE (DD-MM- $Y Y Y Y)$ & 2. REPORT TYPE & 3. DATES COVERED (FrOm - TO)
\end{tabular}

01-09-2007

Technical Memorandum

\section{TITLE AND SUBTITLE}

RF Performance of Membrane Aperture Shells

5a. CONTRACT NUMBER

FA9453-06-M-0155

5b. GRANT NUMBER

5c. PROGRAM ELEMENT NUMBER

\section{AUTHOR(S)}

Flint, Eric, M.; Lindler, Jason, E.; Thomas, David, L.; Romanofsky, Robert

\section{5d. PROJECT NUMBER}

5e. TASK NUMBER

5f. WORK UNIT NUMBER

WBS 439432.07.02.03.01

\section{PERFORMING ORGANIZATION NAME(S) AND ADDRESS(ES)}

National Aeronautics and Space Administration

John H. Glenn Research Center at Lewis Field

Cleveland, Ohio 44135-3191

\section{SPONSORING/MONITORING AGENCY NAME(S) AND ADDRESS(ES)}

National Aeronautics and Space Administration

Washington, DC 20546-0001

\section{PERFORMING ORGANIZATION}

REPORT NUMBER

E-16122

\section{DISTRIBUTIONIAVAILABILITY STATEMENT}

Unclassified-Unlimited

Subject Category: 32

Available electronically at http://gltrs.grc.nasa.gov

This publication is available from the NASA Center for AeroSpace Information, 301-621-0390

\section{SUPPLEMENTARY NOTES}

\section{ABSTRACT}

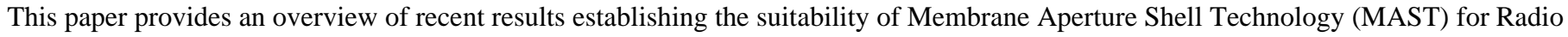
Frequency (RF) applications. These single surface shells are capable of maintaining their figure with no preload or pressurization and minimal boundary support, yet can be compactly roll stowed and passively self deploy. As such, they are a promising technology for enabling a future generation of RF apertures. In this paper, we review recent experimental and numerical results quantifying suitable RF

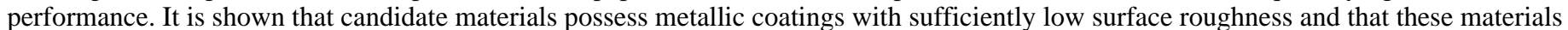

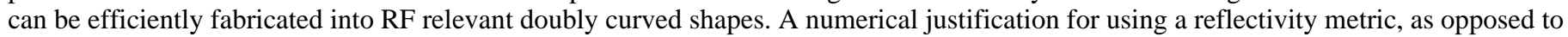
the more standard RF designer metric of skin depth, is presented and the resulting ability to use relatively thin coating thickness is experimentally validated with material sample tests. The validity of these independent film sample measurements are then confirmed

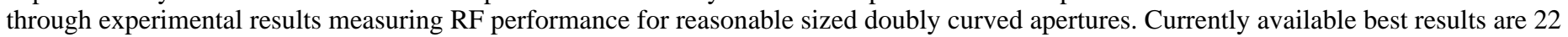

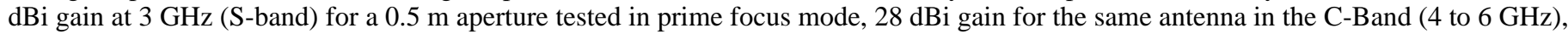
and $36.8 \mathrm{dBi}$ for a smaller $0.25 \mathrm{~m}$ antenna tested at $32 \mathrm{GHz}$ in the Ka-Band. RF range test results for a segmented aperture (one possible

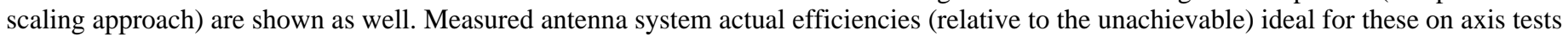
are generally quite good, typically ranging from 50 to 90 percent.

\section{SUBJECT TERMS}

Microwave antennas; Parabolic antennas

\begin{tabular}{|c|c|c|c|c|c|}
\hline \multicolumn{3}{|c|}{ 16. SECURITY CLASSIFICATION OF: } & \multirow{2}{*}{$\begin{array}{l}\text { 17. LIMITATION OF } \\
\text { ABSTRACT } \\
\text { UU }\end{array}$} & \multirow{2}{*}{$\begin{array}{l}\text { 18. NUMBER } \\
\text { OF } \\
\text { PAGES } \\
18\end{array}$} & $\begin{array}{l}\text { 19a. NAME OF RESPONSIBLE PERSON } \\
\text { STI Help Desk (email:help@sti.nasa.gov) } \\
\text { 19b. TELEPHONE NUMBER (include area code) }\end{array}$ \\
\hline $\begin{array}{l}\text { a. REPORT } \\
\mathrm{U}\end{array}$ & $\begin{array}{l}\text { b. ABSTRACT } \\
\text { U }\end{array}$ & $\begin{array}{l}\text { C. THIS } \\
\text { PAGE } \\
\text { U }\end{array}$ & & & $\begin{array}{l}\text { 19b. TELEPHONE NUMBER (include area code) } \\
\text { 301-621-0390 }\end{array}$ \\
\hline
\end{tabular}



